\title{
Beliefs and attitudes towards the influenza vaccine in high-risk individuals
}

\author{
A. J. SANTOS ${ }^{1}$, I. KISLAYA ${ }^{1}$, A. MACHADO $^{1}$ AND B. NUNES ${ }^{1,2}$ \\ ${ }^{1}$ Epidemiology Research Unit/Epidemiology Department, National Health Institute Dr. Ricardo Jorge, \\ Lisbon, Portugal \\ ${ }^{2}$ Centre for Public Health Research, National School of Public Health, NOVA Lisbon University, \\ Lisbon, Portugal
}

Received 19 February 2016; Final revision 1 February 2017; Accepted 18 March 2017; first published online 24 April 2017

\section{SUMMARY}

Societal and economic impact of influenza is mainly due to influenza infection of specific groups, who are at higher risk of health complications leading up to hospitalisation or death. In this study we applied the health belief model (HBM) to evaluate beliefs and attitudes towards influenza disease and vaccine in community-dwelling high-risk individuals (aged 65 or more or having a chronic disease). We conducted a mixed-method study using data collected through a telephone survey of a household unit sample. We used thematic analysis to map responses to HBM dimensions and Poisson regression to model vaccine non-uptake prevalence. The main selfreported reason not to take the vaccine referred to the susceptibility dimension: 'considering oneself to be a healthy person' (29.8\%, (95\% confidence interval (CI) $22 \cdot 1-38 \cdot 7))$. Bad experiences after vaccination - barriers dimension - were also commonly reported $(17 \cdot 0 \%,(95 \%$ CI 10.8-23.8)). Vaccine non-uptake prevalence was $22 \%$ higher in those who did not consider themselves susceptible to contract flu (Prevalence Ratio (PR) $=1 \cdot 22$, (95\% CI $1 \cdot 0-1 \cdot 5)$ ) and $18 \%$ lower in those who did not consider that the vaccine causes flu symptoms (PR $=0 \cdot 82,(95 \% \mathrm{CI}$ $0 \cdot 68-0 \cdot 99)$ ). Results suggest that high-risk individuals do not think of themselves susceptible to influenza infection and fear adverse events following immunisation.

Key words: Chronic disease, elderly, health belief model, high-risk, influenza vaccine, vaccine non-uptake.

\section{INTRODUCTION}

Influenza virus circulates every year, causing epidemics usually benign for the general human population. However, some groups are at an increased risk of developing complications, such as pneumonia. In Portugal, seasonal influenza epidemics have been

\footnotetext{
* Author for correspondence: A. J. Santos, Departamento de Epidemiologia, Instituto Nacional de Saúde Dr. Ricardo Jorge, Av. Padre Cruz, 1649-016 Lisboa, Portugal.

(Email: ana.carvalho@insa.min-saude.pt)
}

associated with an average of $24 \cdot 7$ all-cause excess deaths per 100000 inhabitants and $19 \cdot 4$ pneumonia or influenza excess hospitalisations per 100000 inhabitants, the majority of them among seniors, aged over 65 years [1, 2].

For specific high-risk individuals, yearly vaccination is recommended in most European Union countries, with the intention of reducing their risks of complications, severe disease and death [3-5]. In Portugal, influenza immunisation is recommended to the elderly (over 65 years of age), health professionals, pregnant women (2nd and 3rd trimester) and 
individuals with underlying conditions [6]. Since 2012/ 13 season, influenza vaccination has been offered free of charge and without medical prescription to the population aged over 65 years at the National Health System primary care. Despite the variability of influenza vaccine effectiveness in different seasons and against specific virus type/sub-type [7, 8], influenza vaccination of high-risk individuals has also been reported to be a cost-effective way to decrease mortality and morbidity [6, 9-11].

Despite recommendations of the World Health Organization and immunisation guidelines of many countries recommending vaccination to high-risk individuals, literature indicates that coverage of the influenza vaccination remains low in this target population [6, 9-11]. In Portugal, influenza vaccine coverage is monitored each year [12-15]. Data from 2009/ 10 to 2012/13 seasons show that coverage amongst individuals aged 65 and more ranged between $43 \cdot 4 \%$ (95\% confidence interval $(95 \%$ CI $35 \cdot 5-55 \cdot 7 \%)$ in $2011 / 12$ and $52 \cdot 9 \%(95 \%$ CI $47 \cdot 2-60 \cdot 4 \%)$ in $2009 / 10$ [8-11]. For individuals with at least one chronic disease vaccine coverage ranged between $28 \%(95 \%$ CI $22 \%$ a $34.8 \%)$ in the $2012 / 13$ season and $31 \cdot 0 \%(95 \%$ CI $27 \cdot 2-35 \cdot 1 \%$ ) in $2009 / 10$ [12-15].

Several studies have focused on the reasons for low influenza vaccine coverage. Within the high-risk groups, older adults have been one of the most studied groups [16]. Not having physicians' recommendations, a past bad experience with the vaccine and misconceptions towards it seem to be the most relevant factors associated with vaccine acceptance and uptake within this population [16, 17]. Overall, studies looking at influenza vaccine acceptance predictors, both within high-risk and at-risk populations, highlight the importance and relevance of knowledge, beliefs and attitudes.

Of the several theoretical and empirical models used to evaluate adoption of health preventive behaviours, the health belief model (HBM) is one of the most commonly used as a framework to identify predictors of influenza vaccine acceptance $[16,18]$. First developed as an applicable model by Rosenstock in 1966, the HBM states that specific health behaviours depend on the personal beliefs, perceptions and knowledge about the disease and the available strategies to avoid it [18, 19]. For a person to adopt a new behaviour, he/she needs to believe that the benefits of adopting that behaviour overcome the consequences of maintaining the old one. Overall, the HBM considers five dimensions: (1) susceptibility (a perceived personal vulnerability to a health condition); (2) severity (an individual's belief about the severity of a disease); (3) benefits (perceived positive attributes of an action); (4) barriers (perceived negative aspects related to an action) and (5) cues to action (strategies or information sources that promote the new behaviour) $[18,19]$.

Studies using the HBM to identify predictors of influenza vaccine acceptance have identified reasons related to susceptibility and severity dimensions, such as misconceptions and beliefs about influenza and the vaccine [19-21]. Vaccine side effects are also a significant aspect within the barriers domain and influence the coverage rate, along with logistic difficulties related with the vaccine availability [20]. Even though some dimensions overweight others in predicting this health preventive behaviour, a review of studies on factors predicting influenza vaccine acceptance suggests that the model predicts vaccine uptake [16].

To date there are no population-based studies on influenza vaccine acceptance among high-risk individuals in Portugal. Considering that each society brings its own perspectives and values to the development of a belief system on health and illness, it is important to study specific social contexts when assessing health behaviours [22].

The study aims were to evaluate the knowledge and attitudes towards influenza vaccine acceptance and uptake among high-risk individuals and to measure their associations with vaccine non-uptake.

\section{METHODS}

We conducted a cross-sectional study using the panel of Portuguese families ECOS (Em Casa Observamos Saúde/At home, we observe health), a probabilistic household sample developed by the National Health Institute Doutor Ricardo Jorge (INSA) and in place since 1998/99 [12-15, 23].

\section{ECOS - a panel of Portuguese families}

ECOS is a random sample of Portuguese households stratified and equally distributed by Portugal's five health regions. The ECOS sample consists of a dualframe design (landline and mobile phone), with random selection of telephone numbers from the national landline telephone directory and mobile phone numbers generated through random digit dialling. Households identified through the landline telephone number selection first receive an invitation letter 
from INSA and afterwards a telephone contact to formalise participation. As a mailing address is not available for households identified via a mobile phone number, these are first contacted by telephone and then receive a letter from INSA with the formal invitation. After formal acceptance from the household contact, demographic and health status data are collected for all household members. Every 3 years a new panel is sampled.

\section{Data collection}

The telephone survey, used in the present study, was conducted in December 2013 and comprised approximately 1000 Household Units. Data were collected through a questionnaire applied via CATI (Computer Assisted Telephone Interview) to one element of each household unit aged 18 or more years. The questionnaire covers demographic information, presence of chronic diseases, vaccine uptake during 2013/14 influenza season and the HBM items. All high-risk individuals were asked their level of agreement (5 Likert scale) with 22 closed-ended questions describing the five dimensions of the HBM. Of these, 16 questions related to four of the HBM dimensions (severity, susceptibility, barriers and benefits) and six with the remaining HBM dimension (cues to action).

The items were adapted from previous instruments and statements specifically tailored to evaluate influenza vaccine acceptance among older adults (60 years and over) [12-15, 23]. An open question aimed only at non-vaccinated high-risk individuals was also included: 'What was the main reason for not being vaccinated against the flu in the last season?.

Target population were high-risk individuals, considered as aged 65 years or more or who reported having at least one of the following diagnosed chronic conditions: asthma; chronic obstructive pulmonary disease (chronic bronchitis, pulmonary emphysema); diabetes; obesity; ischemic heart disease (coronary heart disease, angina pectoris); liver disease and kidney disease.

\section{Analysis}

The study comprises a mixed-method approach, including both qualitative and quantitative analysis. We started with a descriptive analysis of the HBM questionnaire closed-ended items for all high-risk individuals characterising the beliefs, perceptions and knowledge about their health, influenza disease and the vaccine.

To understand the views of non-vaccinated highrisk individuals, we asked these participants an openended question on their reasons for not having been vaccinated. We employed thematic content analysis to describe qualitative data obtained through this open-ended question. Thematic content analysis allows for analytical examination of narrative materials by breaking the text into relatively small units of content and submitting them to descriptive treatment [24]. To identify and report patterns (themes) in the respondents' discourse, all non-vaccinated high risk individuals' responses were first transcribed verbatim by interviewers and then systematically coded and categorised in different thematic units. Thematic units were not defined a priori, but developed from the analyses of the open-ended question responses and its content (e.g., a response mentioning being healthy as a reason not to take the vaccine originated the thematic unit 'being healthy/Taking self-care'). Thematic units should be mutually exclusive; we thus reviewed thematic units and some of the response segments were reorganised to ensure that, in an iterative process. We mapped each thematic unit to one of the five dimensions of the HBM where possible, to enable comparison between these results and those of the closed-ended HBM questionnaire.

Recently, several articles in the public health literature $[25,26]$ have pointed out that for cross-sectional studies, when the outcome event is not rare, Poisson regression, which estimates prevalence ratios directly, performs better than logistic regression. Therefore, the relationship between knowledge and attitudes of non-vaccinated high-risk individuals towards the influenza vaccine, measured by the HBM and the prevalence of vaccine non-uptake was assessed using Poisson regression analysis; prevalence ratios of vaccine non-uptake were estimated for the different HBM dimensions variables. We used a stepwise backward elimination procedure to select which variables to include in the final model and in order to find the most parsimonious model. $P$-value of $0 \cdot 05$ was considered as a threshold to eliminate variables from the model in each step. Initial candidate variables were: sex, age groups, education and items translating four of the HBM dimensions (severity, susceptibility, barriers and benefits). Before inclusion in the stepwise backward elimination method the different items in severity and susceptibility dimensions were aggregated and treated as a unique dimension. The cues to action 
Table 1. Distribution of high-risk individuals by sex, age group, schooling and risk group classification

\begin{tabular}{|c|c|c|}
\hline & \multicolumn{2}{|c|}{ Population estimates } \\
\hline & $\%$ & CI $95 \%$ \\
\hline \multicolumn{3}{|l|}{ Sex } \\
\hline Female & $53 \cdot 7$ & $(45 \cdot 7-61 \cdot 6)$ \\
\hline Male & $46 \cdot 3$ & $(38 \cdot 5-54 \cdot 3)$ \\
\hline \multicolumn{3}{|l|}{ Age group } \\
\hline$<45$ & $45 \cdot 7$ & $(39 \cdot 1-52 \cdot 3)$ \\
\hline $45-64$ & 31.9 & $(27 \cdot 1-37 \cdot 0)$ \\
\hline$>65$ & $22 \cdot 4$ & $(18 \cdot 0-27 \cdot 6)$ \\
\hline \multicolumn{3}{|l|}{ Education } \\
\hline$<5$ years of education & $36 \cdot 5$ & $(28 \cdot 9-44 \cdot 8)$ \\
\hline 5-9 years of education & $25 \cdot 7$ & $(19 \cdot 7-32 \cdot 8)$ \\
\hline $10-12$ years of education & $15 \cdot 4$ & $(10 \cdot 5-21 \cdot 9)$ \\
\hline $12+$ years of education & $22 \cdot 5$ & $(16 \cdot 8-29 \cdot 4)$ \\
\hline \multicolumn{3}{|l|}{ Classification } \\
\hline Aged $<65$ years with at least one chronic disease & $46 \cdot 2$ & $(38 \cdot 5-54 \cdot 1)$ \\
\hline Aged $\geqslant 65$ years without chronic disease & $24 \cdot 6$ & $(18 \cdot 6-31 \cdot 7)$ \\
\hline Aged $\geqslant 65$ years with at least one chronic disease & $29 \cdot 3$ & $(22 \cdot 0-37 \cdot 8)$ \\
\hline
\end{tabular}

$\overline{n=399 \text {; estimates weighted by distribution of Portuguese mainland resident population in terms of region, age group and sex. }}$

dimension were excluded, since it was stated differently to the other four. Related to social actions that would drive individuals to uptake the vaccine instead of generally assessing non-vaccination, this dimension is associated with vaccine uptake rather with nonvaccination. All variables with $10 \%$ or more missing values were not considered.

As we aimed to produce population estimates our calculations were weighted. Sampling weights are defined as the inverse of the probability of being included in the sample due to the sampling design. This corresponds to the estimated number of persons in the target population that each ECOS participant represents. Sampling weight calculation included three steps. First, base weights were computed in order to compensate for unequal probabilities of selection by region. Second, base weights were adjusted for landline and mobile phone coverage in Portugal. Finally, sample weights were poststratified to match the distribution of Portuguese mainland resident population in terms of age group and sex. Data analysis was carried out using Stata 12 statistical software.

The ECOS panel of families' survey protocol was approved by the Portuguese Data Protection Authority.

\section{RESULTS}

The response rate of ECOS December 2013 wave was $85 \cdot 5 \%$. Of the total sample $(n=856), 399$ were classified as belonging to the high-risk group - comprising individuals aged 65 or more years or reporting to have a medically diagnosed chronic disease relevant for influenza vaccine recommendation.

Within the high-risk group, $53.7 \%$ were women, $46 \cdot 2 \%$ had $<65$ years of age, but had reported at least one chronic disease, $24 \cdot 6 \%$ were older adults aged 65 or more years with no chronic health conditions and $29 \cdot 3 \%$ were older than 65 and also reported at least one chronic disease (Table 1).

Mostly, study participants had low levels of education; $36 \cdot 5 \%$ had $<5$ years of education and $25 \cdot 7 \%$ between 5 and 9 years of education.

\section{High-risk individuals' assessment of the HBM}

The majority of respondents $(85 \cdot 2 \%)$ seemed to perceive some control on the susceptibility to the disease, disagreeing with 'independently of what I do, I get sick with the flu every year' (Table 2). Respondents recognised that if they became unwell with flu 'they wouldn't get out of bed' (84.7\%). However high-risk individuals did not perceive that flu could be more serious $(96 \cdot 7 \%)$ given 'their condition (chronic disease or age)'. Barriers related to vaccine side effects were evident, with the majority stating that the vaccine produces the same symptoms as the disease $(74 \cdot 2 \%)$.

Regarding the cues to action dimension, a high proportion valued the opinion and suggestion of relatives or people close to them $(74 \cdot 2 \%)$ (Table 3). Vaccine side effects appear, again, as a relevant issue, given 


\begin{tabular}{|c|c|c|c|c|c|c|c|}
\hline \multirow[b]{3}{*}{ HBM model dimensions } & \multirow[b]{3}{*}{ Items } & \multicolumn{6}{|c|}{ Population estimates } \\
\hline & & \multicolumn{2}{|c|}{ Disagree } & \multicolumn{2}{|c|}{$\begin{array}{l}\text { Neither agree or } \\
\text { disagree }\end{array}$} & \multicolumn{2}{|l|}{ Agree } \\
\hline & & $\%$ & CI $95 \%$ & $\%$ & CI $95 \%$ & $\%$ & CI $95 \%$ \\
\hline \multirow[t]{5}{*}{ Severity } & $\begin{array}{l}\text { I can take care of myself and heal me if I get sick with the } \\
\text { flu }(n=396)\end{array}$ & $72 \cdot 2 \%$ & $(63 \cdot 7-79 \cdot 3)$ & $16 \cdot 7 \%$ & $(10 \cdot 6-25 \cdot 4)$ & $11 \cdot 1 \%$ & $(7 \cdot 3-16 \cdot 6)$ \\
\hline & $\begin{array}{l}\text { In my condition (age, chronic disease or pregnancy) } \\
\text { having the flu is serious }(n=398)\end{array}$ & $96 \cdot 7 \%$ & $(93 \cdot 7-98 \cdot 3)$ & $0.5 \%$ & $(0 \cdot 1-3 \cdot 1)$ & $2 \cdot 8 \%$ & $(1 \cdot 4-5 \cdot 6)$ \\
\hline & The flu can cause severe respiratory infections $(n=385)$ & $53 \cdot 5 \%$ & $(43 \cdot 9-62 \cdot 8)$ & $15 \%$ & $(10 \cdot 4-21 \cdot 2)$ & $31 \cdot 5 \%$ & $(22 \cdot 6-42)$ \\
\hline & If I get sick with the flu I cannot get out of bed $(n=394)$ & $5 \cdot 5 \%$ & $(1 \cdot 2-22 \cdot 4)$ & $9 \cdot 8 \%$ & $(5 \cdot 9-15 \cdot 9)$ & $84 \cdot 7 \%$ & $(73 \cdot 5-91 \cdot 6)$ \\
\hline & I'm afraid of getting really sick with the flu $(n=366)$ & $39 \%$ & $(30 \cdot 1-48 \cdot 8)$ & $28 \cdot 6 \%$ & $(21 \cdot 7-36 \cdot 6)$ & $32 \cdot 4 \%$ & $(23 \cdot 2-43 \cdot 2)$ \\
\hline \multirow[t]{3}{*}{ Susceptibility } & Due to my age, my health is fragile $(n=387)$ & $24 \cdot 2 \%$ & $(17 \cdot 3-32 \cdot 9)$ & $14 \cdot 5 \%$ & $(9 \cdot 6-21 \cdot 3)$ & $61 \cdot 3 \%$ & $(5 \cdot 3-69 \cdot 1)$ \\
\hline & I am careful with myself and rarely get sick $(n=395)$ & $69 \cdot 3 \%$ & $(61 \cdot 2-76 \cdot 3)$ & $19 \%$ & $(12 \cdot 8-27 \cdot 2)$ & $11 \cdot 7 \%$ & $(8 \cdot 1-16 \cdot 6)$ \\
\hline & $\begin{array}{l}\text { Independently of what I do, I get sick with the flu every } \\
\text { year }(n=394)\end{array}$ & $85 \cdot 2 \%$ & $(78 \cdot 5-90)$ & $4 \cdot 9 \%$ & $(9 \cdot 6-21 \cdot 3)$ & $9 \cdot 9 \%$ & $(6 \cdot 2-15 \cdot 5)$ \\
\hline \multirow[t]{7}{*}{ Barriers } & If you get the flu shot you get flu symptoms $(n=378)$ & $11 \cdot 6 \%$ & $(7 \cdot 8-17 \cdot 0)$ & $14 \cdot 2 \%$ & $(9 \cdot 3-20 \cdot 9)$ & $74 \cdot 2 \%$ & $(66 \cdot 7-80 \cdot 4)$ \\
\hline & $\begin{array}{l}\text { I have difficulties getting an appointment with my doctor } \\
(n=321)\end{array}$ & $31 \cdot 0 \%$ & $(23 \cdot 7-39 \cdot 5)$ & $21 \cdot 2 \%$ & $(13 \cdot 6-31 \cdot 5)$ & $47 \cdot 8 \%$ & $(39 \cdot 1-56 \cdot 6)$ \\
\hline & I'm against all type of vaccines $(n=397)$ & $68 \cdot 7 \%$ & $(61 \cdot 3-75 \cdot 3)$ & $5 \cdot 1 \%$ & $(3 \cdot 0-8 \cdot 6)$ & $26 \cdot 2 \%$ & $(20 \cdot 0-33 \cdot 4)$ \\
\hline & Vaccines are very expensive $(n=397)$ & $83 \cdot 8 \%$ & $(76 \cdot 3-89 \cdot 2)$ & $7 \cdot 3 \%$ & $(3 \cdot 9-13 \cdot 2)$ & $8.9 \%$ & $(5-15 \cdot 4)$ \\
\hline & I have had a bad experience with the flu shot $(n=279)$ & $33 \%$ & $(25 \cdot 3-41 \cdot 7)$ & $34 \cdot 6 \%$ & $(26 \cdot 7-43 \cdot 5)$ & $32 \cdot 3 \%$ & $(25-40 \cdot 8)$ \\
\hline & $\begin{array}{l}\text { The last time I tried to get the flu shot there was a shortage } \\
(n=323)\end{array}$ & $78 \cdot 6 \%$ & $(70 \cdot 0-85 \cdot 2)$ & $5 \cdot 4 \%$ & $(2-13 \cdot 7)$ & $15 \cdot 9 \%$ & $(10 \cdot 6-23 \cdot 3)$ \\
\hline & $\begin{array}{l}\text { I have mobility difficulties and I can only go to the doctor } \\
\text { if someone takes me }(n=279)\end{array}$ & $76 \cdot 9 \%$ & $(60 \cdot 4-87 \cdot 8)$ & $17 \cdot 7 \%$ & $(7 \cdot 6-36 \cdot 4)$ & $5 \cdot 4 \%$ & $(2 \cdot 9-9 \cdot 6)$ \\
\hline Benefits & The flu vaccine protects people from the flu $(n=387)$ & $11 \cdot 2 \%$ & $(7 \cdot 3-16 \cdot 8)$ & $18 \cdot 8 \%$ & $(12 \cdot 5-27 \cdot 4)$ & $69 \cdot 9 \%$ & $(61 \cdot 5-77 \cdot 3)$ \\
\hline
\end{tabular}

questionnaire

Estimates weighted by distribution of Portuguese mainland resident population in terms of region, age group and sex. 
a large part (61.3\%) states that 'knowing sufficient information on protection and safety of the vaccine' could lead them to take it.

\section{Reasons for not having taken the vaccine - non-vaccinated individuals}

Only about one third of the high-risk individuals reported to have taken the influenza vaccine $(31 \cdot 3 \%$, (95\% CI 24.6-39.0)) during the 2013/14 season $(n=279)$. Analysis of the open-ended question to high-risk individuals reporting not to have been vaccinated resulted in 15 mutually exclusive thematic units, the majority of which could be mapped to the five dimensions of the HBM (Table 4). Two did not apply to the HBM dimensions: 'It's not a habit/Just because' and 'Can't because he/she is already sick'.

Two of the most frequent thematic units found, regarded the susceptibility dimension of the HBM, which encompassed a total of three thematic units: 'being healthy' (29.8\%); 'never or rarely getting sick with flu or a cold' (19.3\%) and 'not being part of the high-risk group' (11.9\%) (Table 4). The observed responses suggest that individuals tend to minimise the risk of influenza infection because they perceived themselves as healthy and careful individuals, not included in the high-risk group. Some examples were 'I take a lot of vitamin $\mathrm{C}$ from the oranges' and 'never or rarely catching flu or having a cold'.

The second most common dimension of the HBM model was barriers, including physical, logistic, emotional and cognitive difficulties. Our results indicate that perceived emotional and cognitive barriers tended to be more relevant, as these were the most frequently reported. Specifically, the thematic unit regarding the vaccine side effects ('previous own/others bad reaction/ it's worse than the flu') was the most frequent thematic unit $(16.9 \%)$. The perception of vaccine side effects and its danger while not explicit is also present in the second most reported thematic unit of the barriers dimension - fear $(7 \cdot 8 \%)$.

Only one thematic unit regarding the cues to action dimension emerged from the open-ended responses. It encompassed both the fact that the doctor did not specifically advise to take the vaccine and the fact that doctor advised against it $(5 \cdot 5 \%)$.

\section{Prevalence of vaccination non-uptake}

Prevalence of vaccine non-uptake associated factors was assessed using Poisson regression analysis. A

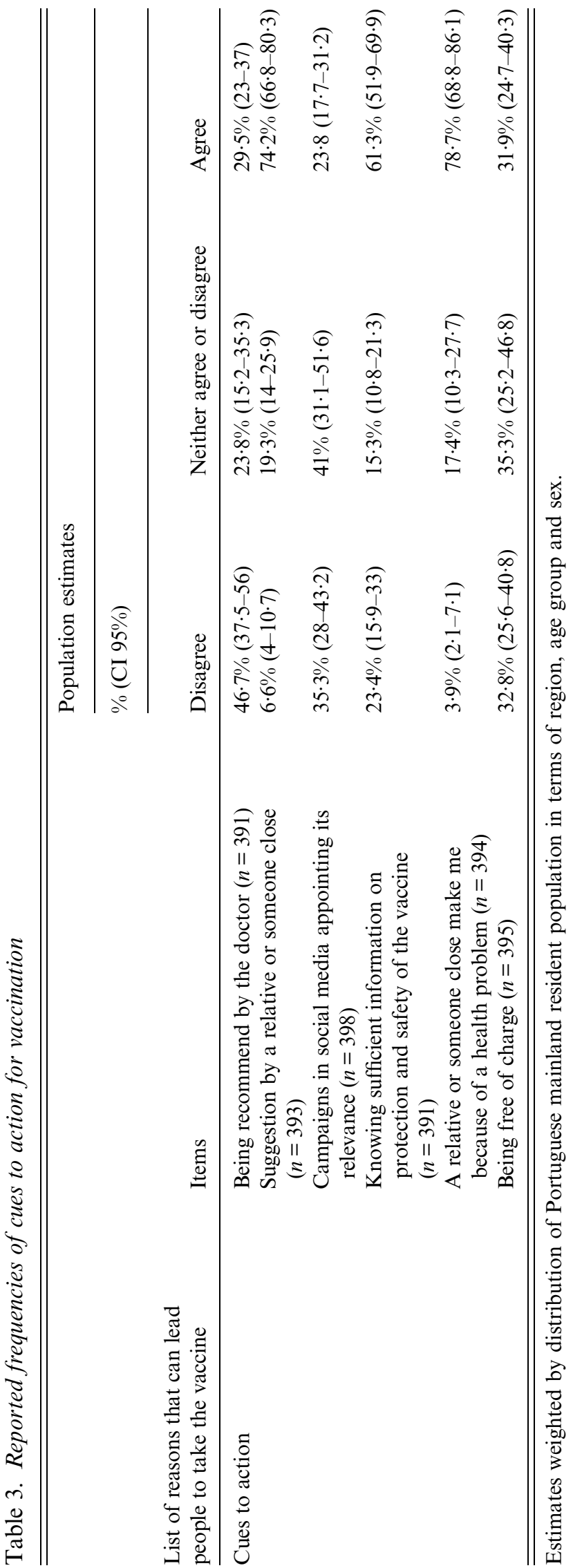




\begin{tabular}{|c|c|c|c|c|}
\hline \multirow[b]{2}{*}{ HBM model dimensions } & \multirow[b]{2}{*}{ Thematic Units* } & \multirow[b]{2}{*}{ Responses examples* } & \multicolumn{2}{|c|}{ Population estimates } \\
\hline & & & $\%$ & CI $95 \%$ \\
\hline Perceived severity & $\begin{array}{l}\text { Flu as something normal/something that one } \\
\text { goes throw easily }\end{array}$ & $\begin{array}{l}\text { 'I don't think I need it because the flu is } \\
\text { something normal that one takes care with } \\
\text { homemade remedies' }\end{array}$ & $0 \cdot 6 \%$ & $(0 \cdot 1-3 \cdot 5)$ \\
\hline Susceptibility & Being healthy/taking self-care & $\begin{array}{l}\text { 'I'm healthy and do not consider vaccination' } \\
\text { and 'I take a lot of } \mathrm{C} \text { vitamin from the oranges' }\end{array}$ & $29 \cdot 8 \%$ & $(22 \cdot 1-38 \cdot 7)$ \\
\hline \multirow{7}{*}{ Barriers } & $\begin{array}{l}\text { Not being part of the high-risk group/not } \\
\text { having health problems }\end{array}$ & 'I'm not a risk person, given I'm not elderly' & $11 \cdot 9 \%$ & $(7 \cdot 5-18 \cdot 3)$ \\
\hline & Never/rarely gets sick with the flu/cold & 'I never have much flu' 'I have never had a cold' & $19 \cdot 3 \%$ & $(13 \cdot 3-27 \cdot 1)$ \\
\hline & Vaccine shortage/expensiveness & 'They ran out of vaccine in the pharmacy' & $5 \cdot 3 \%$ & $(1 \cdot 6-15 \cdot 937)$ \\
\hline & $\begin{array}{l}\text { Previous own/others bad reaction/it is worse } \\
\text { than the flu }\end{array}$ & $\begin{array}{l}\text { 'Relatives whom had the shot died shortly after, } \\
\text { one of them was diabetic' }\end{array}$ & $17 \cdot 0 \%$ & $(10 \cdot 8-23 \cdot 8)$ \\
\hline & Not effective/there are healthier measurements & 'I do not believe in the vaccine' & $2 \cdot 3 \%$ & $(0 \cdot 9-5 \cdot 7)$ \\
\hline & Fear & 'I am afraid' & $7 \cdot 8 \%$ & $(2 \cdot 3-23 \cdot 2)$ \\
\hline & $\begin{array}{l}\text { Does not have a general practitioner/didn't get } \\
\text { an appointment }\end{array}$ & 'Couldn't get an appointment with my doctor' & $0 \cdot 6 \%$ & $(0 \cdot 2-2 \cdot 5)$ \\
\hline \multirow{4}{*}{$\begin{array}{l}\text { Cues to action } \\
\text { Other motives }\end{array}$} & Lack of opportunity/time & 'I haven't had the opportunity' & $2 \cdot 8 \%$ & $(1 \cdot 0-7 \cdot 8)$ \\
\hline & Doctor didn't advise it or advised against it & 'My general practitioner did not said to take it' & $5 \cdot 5 \%$ & $(2 \cdot 2-13 \cdot 0)$ \\
\hline & It's not an habit/just because & 'I never get the flu shot' & $12 \cdot 7 \%$ & $(7 \cdot 7-20 \cdot 2)$ \\
\hline & Can't because his/her already sick with the flu & 'I can't because I'm sick' & $1 \cdot 6 \%$ & $(0 \cdot 6-4 \cdot 0)$ \\
\hline
\end{tabular}


Table 5. Vaccine non-uptake prevalence ratios (PR) adjusted for Poisson regression model for HBM dimensions (susceptibility and severity)

\begin{tabular}{lllll}
\hline \hline & & & PR & IC 95\% \\
\hline Age groups & & $<45$ & 1 & - \\
& & $45-64$ years & $0 \cdot 97$ & $(0 \cdot 82-1 \cdot 15)$ \\
\multirow{3}{*}{ Susceptibility } & \multirow{2}{*}{ I am/ can be susceptible to the flue } & $65+$ & $0 \cdot 60^{* *}$ & $(0 \cdot 47-0 \cdot 71)$ \\
& & Neither agree nor disagree & 1 & - \\
& & Agree & $0 \cdot 66$ & $(0 \cdot 42-1 \cdot 04)$ \\
Barriers & \multirow{2}{*}{ If you get the flu shot you get flu symptoms } & Do not agree & $1 \cdot 22^{*}$ & $(1 \cdot 01-1 \cdot 50)$ \\
& & Neither agree nor disagree & 1 & - \\
& & Agree & $1 \cdot 01$ & $(0 \cdot 87-1 \cdot 38)$ \\
& & Do not agree & $0 \cdot 82^{*}$ & $(0 \cdot 68-0 \cdot 99)$ \\
\hline \hline
\end{tabular}

$* P<0 \cdot 05 ; * * P<0 \cdot 01$

total of nine variables were initially considered: sex, age group, education, severity, susceptibility, benefits and three items from the barriers dimension. Unlike items from the other HBM dimensions, those from the barriers dimension were not aggregated and were included individually. Of the seven items initially included in that dimension only three items were considered ('If you get the flu shot you get flu symptoms'; 'I'm against all type of vaccines' and 'Vaccines are very expensive'), given the high percentage of missing values $(>10 \%)$ on the other four items.

From the initial model (Table 5) and after the backward stepwise elimination method and deletion of variables with a $P$-value $>0 \cdot 05$, the final model comprised 3 variables: age groups, the susceptibility dimension and one item from the barriers dimension. Not considering oneself susceptible to the influenza infection increased non-vaccination prevalence by $22 \%$. In the barriers dimension, the prevalence of nonvaccination decreases by $18 \%$ for those who do not consider that the vaccine causes flu symptoms.

\section{DISCUSSION}

The results of our study indicate that influenza vaccine coverage among high-risk individuals (aged 65 or more years or reporting a chronic disease) is low (31.3\%). This emphasises the need for public policies in order to comply with the World Health Organization recommendation of $75 \%$ coverage among this group of individuals [27].

Perceived susceptibility has been reported as one of the most relevant dimensions in adopting preventive health behaviours [18]. Our results, from both the quantitative and qualitative analysis, support this. On the one hand, high-risk individuals do not consider themselves susceptible to flu. On the other hand, highrisk, non-vaccinated individuals believe influenza can be prevented by measures other than the vaccine.

Our results also show that the high-risk group studied had misconceptions, insufficient knowledge and lack of awareness regarding susceptibility. Misconceptions about the influenza was one of the most common reasons provided by high-risk individuals from four European countries [27] and is associated with vaccine non-uptake in other populations groups, namely, health care workers, elderly and healthy adults [11, 16, 28-31]. Still within the susceptibility domain, another important aspect from both the quantitative and qualitative results is the self-knowledge on belonging to the high-risk group, even though $75.5 \%$ of all high risk individuals reported a relevant chronic disease. Similarly, within the non-vaccinated high-risk individuals one common reason for non-vaccination was the belief about not qualifying for vaccination. This group's lack of awareness of the risks of complications due to their chronic disease also relates to the severity domain of the HBM. The large majority of all high-risk individuals (96.7\%) do not believe that, in their condition (age or chronic disease), having the flu could exacerbate their underlying condition. Previous studies have also found the lack of knowledge about the risk status of this population [27].

Another usually relevant domain in vaccination coverage is barriers, regarded as one of the most important constructs in determining behaviour change $[19,28]$. Even with correct information on the threat of a particular disease, barriers can exert a greater influence than the threat itself [16]. There is usually a division between practical barriers, concerning the individuals' resources and the vaccine availability and the individuals' cognitive and emotional barriers 
to undertake the new behaviour [19]. The results from the close-ended questions do not suggest the costs of the vaccine or vaccine shortage as major recognised barriers, whereas the flu symptoms produced by the vaccine were a recognised issue among the majority of high-risk individuals. Barriers associated with 'fear of side effects and having/know a bad experience with the flu shot' only become relevant within the open-ended questions and non-vaccinated individuals. Fear of side effects is a commonly provided reason for vaccine refusal among different target groups [16, 17, $21,22,27,30]$ and was, in our study, particularly important among the non-vaccinated high-risk individuals.

Previous studies, using different populations, have reported susceptibility, perceived effectiveness of the vaccine and its side effects (barriers), physician recommendation and receiving a reminder as nonvaccination status predictors $[16,17,21,27,30]$. In our study perceived susceptibility and barriers domains predicted the non-vaccination status. Vaccine side effects, specifically the flu symptoms were invoked by about $74 \%$ of all high-risk individuals and this aspect was also a frequent motive not to be vaccinated. The severity dimension, a usually encountered aspect in other studies [16, 17, 21, 27, 30] was not found as relevant in the open-ended or in the Poisson regression model. Overall, results indicated that unvaccinated individuals considered not being susceptible to influenza more relevant than the severity or disease impact. This suggests that individuals in risk groups fail to recognise themselves as part of the population targeted for influenza vaccination. This was found in both non-vaccinated and vaccinated high-risk individuals. This group did not perceive flu could be more serious in their condition. The distinction between susceptibility and severity in the results of thematic groups analysis may be a limitation of the study, as non-recognition of belonging to a risk group might affect the perception of disease severity.

It is important to keep in mind that perceptions may change over time, because risk assessment is embedded in social and cultural contexts [31] and the study cross-sectional nature hampers results generalisation for different time periods. Second, the problem of information bias applies to both the chronic disease and the vaccine uptake questions, which were self-reported [23]. Furthermore, the questionnaire employed to assess HBM dimensions was not validated in the Portuguese population, which can pose validity issues, specifically when assessing misconceptions.

The mixed method approach allowed us to evaluate the perception, knowledge and beliefs towards influenza disease and vaccine - by assessing the level of agreement with several close-ended questions from the close-ended questionnaire - but also by capturing individuals' perceptions and beliefs regarding the decision making process of not taking the vaccine. By capturing 'unfiltered' salient perceptions and beliefs, without a set of preconceived items, we were able to observe the role and relevance of some of the HBM dimensions (susceptibility, barriers) over the remaining ones.

In summary, the susceptibility and barriers domains of the HBM seem to be the most relevant in explaining vaccine non-uptake, thus emphasising the importance of misconceptions about influenza and the vaccine. These dimensions should be used to design future public campaigns. The susceptibility dimension points out the importance of information on who qualifies for vaccination - high-risk groups - and influenza infection (how one can be infected by the influenza virus). Information on the possible outcomes of the disease should be included given individuals may be unaware not only that they are at risk (susceptibility), but also of the diseases possible complications to high-risk individuals (severity). Finally, the importance of fear of the vaccine (barriers) indicates that it is crucial to address its adverse effects. Educating individuals about the vaccine benefits and potential side effects may positively impact on the vaccine coverage rates.

\section{SUPPLEMENTARY MATERIAL}

The supplementary material for this article can be found at https://doi.org/10.1017/S0950268817000814.

\section{ACKNOWLEDGEMENT}

This research received no specific grant from any funding agency, commercial or not-for-profit sectors.

\section{DECLARATION OF INTEREST}

None.

\section{ETHICAL STANDARD}

The authors assert that all procedures contributing to this work comply with the ethical standards of the relevant national and institutional committees on 
human experimentation and with the Helsinki Declaration of 1975 , as revised in 2008.

\section{REFERENCES}

1. Nunes B, et al. Excess mortality associated with influenza epidemics in Portugal, 1980 to 2004. PLoS ONE 2011; 6: e20661.

2. Rodrigues E, Machado A, Nunes B. Excess pneumonia and influenza hospitalizations associated with influenza epidemics in Portugal from 1998 to 2010. Proceedings from IEA-EEF European Congress of Epidemiology, Epidemiology for a Fair and Healthy Society. Porto, Portugal: Instituto Nacional de Saúde Doutor Ricardo Jorge, IP, 2012.

3. Oropesa $\mathbf{S}$, et al. The impact of influenza vaccination in the reduction of morbidity and in the exacerbation in asthmatic patients. International Congress Series 2004; 1263: 355-359.

4. Nichol KL. Influenza vaccination in the elderly: impact on hospitalisation and mortality. Drugs Aging 2005; 22: 495-515.

5. World Health Organization. Vaccines against Influenza WHO Position Paper. Weekly Epidemiological Record: Weekly Epidemiological Record. Geneva, Switzerland: World Health Organization, 2012. (Position papers; vol. 87 , no. 47 ).

6. Direção Geral de Saúde. Orientação da Direção-Geral de Saúde. Vacinação contra a gripe com a vacina trivalente para a época 2015-2016. Lisboa, Portugal: Direção Geral de Saúde, 2015.

7. Kissling $\mathbf{E}$, et al. I-MOVE multi-centre case control study 2010-11: overall and stratified estimates of influenza vaccine effectiveness in Europe. PLoS ONE 2011; 6: e27622.

8. Nunes B, et al. Efectividade da vacina antigripal na época 2010-2011 em Portugal: resultados do projeto EuroEVA. Revista Portuguesa de Medicina Geral e Familiar 2012; 28: 271-284.

9. World Health Organization. Meeting of the Strategic Advisory Group of Experts on Immunization, October 2014 - Conclusions and Recommendations Weekly Epidemiological Record. Geneva, Switzerland: World Health Organization, 2014.

10. Fedson DS, et al. Influenza vaccination in 18 developed countries, 1980-1992. Vaccine 1995; 13: 623-627.

11. Tsui HY, et al. Prevalence of seasonal influenza vaccination and associated factors in people with chronic diseases in Hong Kong. Epidemioly and Infection 2013; 141: 377-389.

12. Branco MJ, Paixão E, Nunes B. Vacinação antigripal da população portuguesa, em 2009-2010: cobertura e algumas características do acto vacinal [Influenza vaccine in portuguese population, 2009-2010 season: coverage and characteristics]. Lisboa, Portugal: Instituto Nacional de Saúde Doutor Ricardo Jorge, 2010.

13. Branco MJ, Nunes B. Vacinação antigripal da população portuguesa, em 2010-2011: cobertura e algumas caracterísitcas do acto vacinal [Influenza vaccine in portuguese population, 2010-2011 season: coverage and characteristics]. Lisboa, Portugal: Instituto Nacional de Saúde Doutor Ricardo Jorge, 2011.

14. Nunes B, Branco MJ. Vacinação antigripal da população portuguesa, em 2011-2012: cobertura e características do acto vacinal [Influenza vaccine in portuguese population, 2011-2012 season: coverage and characteristics]. Lisboa, Portugal: Instituto Nacional de Saúde Doutor Ricardo Jorge, 2012.

15. Sousa-Uva M, et al. Vacinação antigripal da população portuguesa na época 2012-2013: estudo da amostra ECOS [Influenza vaccine in portuguese population, 2012-2013 season: ECOS sample study]. Lisboa, Portugal: Instituto Nacional de Saúde Doutor Ricardo Jorge, 2013.

16. Chapman GB, Coups EJ. Predictors of influenza vaccine acceptance among healthy adults. Preventive Medicine 1999; 29: 249-262.

17. Nowak G. Increasing awareness and uptake of influenza immunization. In: Knobler SL, Mack A, Mahmoud A, Lemon SM, eds. The Threat of Pandemic Influenza: are we Ready? Workshop Summary. Washington, DC: National Academies Press (US), 2005, pp. 235-248.

18. Ogden J. Health Psychology: a Text Book. Berkshire, England: McGrawHill Education, 2004.

19. Champion VL, Skinner CS. Health belief model. In: Glanz $\mathrm{K}$, Rimer BK, Viswanath K, eds. Health Behavior and Health Education: Theory, Research, and Practice. San Francisco, USA: John Wiley \& Sons, 2008, pp. 42-65.

20. Blue CL, Valley JM. Predictors of influenza vaccine. Acceptance among healthy adult workers. American Association of Occupational Health Nurses Journal 2002; 50: 227-233.

21. Evans MR, Watson PA. Why do older people not get immunised against influenza? A community survey. Vaccine 2003; 21: 2421-2427.

22. Kroneman M, van Essen GA, Paget JW. Influenza vaccination coverage and reasons to refrain among highrisk persons in four European countries. Vaccine 2006; 24: 622-628.

23. Pinto CS, et al. Trends in influenza vaccination coverage in Portugal from 1998 to 2010: effect of major pandemic threats. BMC Public Health 2013; 13: 1130-1136.

24. Sparker A. Narrative analysis: exploring the whats and hows of personal stories. In: Holloway I, ed. Qualitative Research in Health Care. Berkshire: Open University Press, 2005, pp. 191-208.

25. Barros AJD, Hirakata VN. Alternatives for logistic regression in cross-sectional studies: an empirical comparison of models that directly estimate the prevalence ratio. BMC Medical Research Methodology 2003; 3: 21. doi: 10.1186/1471-2288-3-21.

26. McNutt LA, et al. Estimating the relative risk in cohort studies and clinical trials of common outcomes. American Journal of Epidemiology 2003; 157: 940-943.

27. Blank PR, Schwenkglenks M, Szucs TD. Disparities in influenza vaccination coverage rates by target group in five European countries: trends over seven consecutive seasons. Infection 2009; 37: 390-400. 
28. Nguyen-Van-Tam JS, Nicholson KG. Influenza immunization; vaccine offer, request and uptake in high-risk patients during the 1991/2 season. Epidemiology and Infection 1993; 111: 347-355.

29. Janz NK, Becker MH. The health belief model: a decade later. Health Education Quarterly 1984; 11: 1-47.
30. Cornford CS, Morgan M. Elderly people's beliefs about influenza vaccination. British Journal of General Practice 1999; 49: 281-284.

31. Tate RB, et al. Change in health risk perception following community intervention in Central Havana, Cuba. Health Promotion International 2003; 18: 279-286. 